\title{
Editorial
}

\section{Para socios y profesionales afines a la salud de la mujer}

\section{Estimados Socios y Profesionales afines a la Salud de la Mujer,}

Este suplemento especial, dedicado completamente a publicaciones nacionales relacionadas a COVID-19, es un sencillo gesto de homenaje de nuestra Revista a quienes han cuidado de las mujeres en este periodo de Pandemia.

En este gesto, queremos reconocer a quienes han estado trabajando de manera incesante en la atención directa de las pacientes. Este reconocimiento no es sólo por el esfuerzo físico y desgaste emocional que esto ha significado, sino también por la empatía y responsabilidad social con la que han realizado su labor.

Agradecer enormemente el liderazgo demostrado por los Jefes de Turno y Jefes de Servicio de todo nuestro país, quienes han coordinado y planificado el trabajo no solo para cumplir las metas asistenciales, sino también para ofrecer un trabajo seguro a los equipos de salud. No podemos dejar fuera de este reconocimiento a todos los profesionales que salieron de sus labores habituales y volvieron a hacer turnos para apoyar el duro trabajo que ocurrió en las Urgencias. Dedicamos un lugar especial a la APS, donde con innovación y esfuerzo, se logró mantener el seguimiento y control de las miles de embarazadas durante este periodo. La coordinación entre los diferentes niveles de cuidado fue el elemento esencial que permitió ofrecer continuidad en la atención a las pacientes.

Sin duda que esta Pandemia, nos ha golpeado en todos los aspectos de nuestras vidas, y nos ha dejado con múltiples desafíos. La Sociedad Chilena de Obstetricia y Ginecología, desde un comienzo, ha participado en diferentes mesas de trabajo organizadas por el MINSAL y el Colegio Médico de Chile. Ha colaborado en la formación de los profesionales a través de la realización de seminarios virtuales de acceso libre. A través de su pagina Web y redes sociales, ha divulgado las guías clínicas realizadas por Universidades y el MINSAL. Las
Maternidades de diferentes Hospitales de Chile compartieron su experiencia, de éxitos y fracasos en el enfrentamiento de esta pandemia, a través de los Webinar. Sin duda, entre todos, fuimos capaces de construir la empalizada protectora, alrededor de los servicios de Salud de la mujer. Esto ha permitido mantener a salvo a embarazadas, puérperas, junto a sus recién nacidos y mujeres que han necesitado asistencia y cuidado en diferentes aspectos de la salud sexual y reproductiva.

Este número especial, con 17 trabajos relacionados a la experiencia chilena en COVID-19, ha significado un esfuerzo editorial importante de nuestro Editor General (Dr. Mauricio Cuello), de los Editores Invitados (Dr. Alvaro Insunza y Dr. José Andrés Poblete), de nuestra coordinadora (Karina Carrasco), y de todos los especialistas que dedicaron varias horas a evaluar los trabajos para su publicación. A través de este suplemento hacemos la invitación a mejorar los aspectos necesarios para realizar una coordinación eficiente entre los diferentes niveles de atención en salud. Además, hacemos un llamado a la generación local de nuevo conocimiento que nos permita resolver los desafíos sanitarios y de esta manera, brindar una atención de calidad, con equidad y justicia, a nuestras pacientes a lo largo y ancho de nuestro país.

Un abrazo sincero,

Dr. José Andrés Poblete

Presidente

Sociedad Chilena de Obstetricia y Ginecología. 